\title{
A STEP INTO THE LIGHT: DEVELOPING A CULTURALLY APPROPRIATE RESEARCH PROCESS TO STUDY MĀORI RANGATAHI PERSPECTIVES OF LEISURE IN ONE SETTING
}

\author{
GERALDINE HARVEY \\ Department of Sport and Leisure Studies Masters student \\ The University of Waikato
}

\begin{abstract}
There is little knowledge of Māori peoples' leisure understandings, experiences and participation. This article reports on the development of a culturally appropriate research process that investigated the leisure participation, perspectives, and experiences of five Rotorua Māori Rangatahi in one research setting ${ }^{1}$. Within this exploration there is a focus on the need to conduct leisure research with Mäori people in culturally appropriate ways. This research approach incorporates focus group methodology within a Kaupapa Māori research framework which addresses issues of research for Māori. The research process revealed that focus group methodology can be adapted into a Kaupapa Māori research framework and that this research approach could be an important tool when conducting research with Mäori Rangatahi, including in educational contexts.
\end{abstract}

\section{INTRODUCTION}

There is little research on how Māori view leisure, our understandings of leisure, our leisure experiences or our leisure participation. Due to the general lack of research in this area, it is difficult to know whether leisure providers are in fact meeting the leisure needs of Māori. McGregor and McMath (1993) suggest that leisure and recreation workers need to be cognisant of the inherent diversity between cultures as many Māori may have different views on leisure, participate in a wider variety of activities they define as leisure, and participate in leisure for quite different reasons than those of non-Māori.

Thompson, Rewi and Wrathall (2000) argue that in order to gain understandings of Māori leisure experiences, participation, and perspectives a culturally appropriate research approach is needed. Smith (1998) further suggests that leisure research conducted with Māori people needs to be carried out by Māori people, as the maximum benefits of the research will be for Māori people.

With these considerations in mind, this article reports on the development of a culturally appropriate way of investigating Māori Rangatahi perspectives of leisure that combined both western and Māori approaches. Thus, the research was

\footnotetext{
1 This paper is conducted within an indigenous approach to leisure research. Therefore, within the scope of this paper Te Reo Maori is used in text without translation. However, a glossary is provided at the end of this paper with the nearest English translation.
} 
conducted using focus group methodology within a Kaupapa Māori research context.

First, I set the scene and position myself as the researcher and this leisure investigation in terms of working within a Kaupapa Māori research framework. Following this, I then examine the literature related to Kaupapa Māori research approaches and focus group methodology. Within the methodological principles section I focus on the process of developing a research approach that incorporates focus group methodology within a Kaupapa Māori research framework. In the following section I explain the research process. In the discussion and conclusion sections I reflect on the use of focus group methodology within a Kaupapa Māori research framework.

\section{SETTING THE SCENE}

\section{Positioning Myself Within the Research Process}

Ngongotaha te Maunga, Rotorua nui a Kahumatamamoe te moana, Te Arawa te Waka, Te Arawa te Iwi, Ko Ngati Whakaue me Tuhoe oku hapu, Te Papa I Oru te Marae, No Rotorua ahau, Ko Geraldine Hera taku ingoa, No reira, Tena Koutou, Tena Koutou, Kia ora mai tatou katoa.

The above mihi acknowledges where I am from in terms of the land, iwi, and hapu. Within this research process, I position myself as a young Māori woman using a Kaupapa Māori research framework to conduct leisure research with Māori rangatahi in Rotorua ${ }^{2}$.

\section{Positioning the Research in the Aotearoa New Zealand Context}

The history of Māori and Pākehā relations since Aotearoa was colonised and Te Tiriti O Waitangi was signed has not been one of partnership (Walker, 1990). Instead, it has been one of cultural assimilation and domination by Pākehā and marginalisation of Māori. Māori have, since the earliest contact with Pākehā people, demonstrated reluctance to being observed and researched on Pākehā terms (Smith, 1992). Researchers in Aotearoa, who have been primarily Pākehā, have often undervalued and belittled Māori knowledge, perspectives, experiences, learning practices, and processes whilst enhancing those of the colonisers. Smith (1999) states that:

The collective memory of imperialism has been perpetuated through the ways in which knowledge about indigenous peoples was collected, classified and then represented in various ways back to the West, and then, through the eyes of the West, back to those who have been colonised ( $\mathrm{p} 1)$.

In addition, Pākehā researchers have been criticised for undertaking Māori research using their own agendas and research methods without taking into consideration the cultural practices associated with the passing on of knowledge.

${ }^{2}$ In 2002, I completed a Masters Thesis entitled 'Out of the Mist Into the Light: The leisure perspectives of a small group of Rotorua Maori Rangatahi'. In this article I draw from my experiences of the research process in the above study. 
Jahnke and Taiapa (1999) suggest that much of the research done on Mãori in the past has been of little benefit to Māori themselves and tends to emphasise negative statistics without providing information to make a positive change.

As well as conventional research not having addressed Māori needs and understandings, 'sport' and 'leisure' in Aotearoa New Zealand are Pākehā constructs imposed on Māori, through assimilation and social control by Pākehā (McConnell, 2000). The essence of McConnell's (2000) argument lies in the fact that leisure has been defined by Pākehā, imposed on Māori and then controlled by Pākehā with little regard for the holistic understandings of life in a Māori world. In addition, Smith (1998) also suggests that it is important to examine Māori attitudes to leisure apart from the dominant western definitions. It is important first to acknowledge that there are differences in how different cultures may perceive leisure and then to understand these differences in perspectives. In order for leisure research to be of benefit it needs to be led by Māori and/or conducted according to appropriate cultural practices.

These concerns have led to a growing need to establish research approaches that take into consideration the Aotearoa context and culturally appropriate ways to deal with knowledge. Māori researchers are challenging the dominance of western methodologies that have conventionally dominated research into Māori lives and Māori knowledge. Kaupapa Māori research has emerged in Aotearoa as an indigenous approach that challenges the hegemony of the dominant discourses of research (Bishop, 1996b).

\section{LITERATURE REVIEW}

\section{Kaupapa Māori Research}

Smith (1994) proposes that Kaupapa Māori research is a counter-hegemonic approach to western forms of research and, as such, exists outside western research. Kaupapa Māori research is collectivistic, meaning that it includes not only the researcher and research participants, but also considers other factors associated with the investigation including cultural practices.

Kaupapa Māori research is based on a growing consensus that research involving Māori knowledge and people needs to be conducted in culturally appropriate ways, ways that fit Māori cultural preferences, practices, and aspirations in order to develop and acknowledge existing culturally appropriate approaches in the method, practice and organisation of research. (Bishop, 1996b, p. 15)

Kaupapa Māori research is orientated toward benefiting all research participants and their agendas, defining and acknowledging Māori aspirations for research, and developing and implementing Māori theoretical and methodological preferences and practices for research (Bishop, 1996a). Further, Kaupapa Māori research aims to ensure the research meets and works within the interests and concerns of participants (Bishop, 1996a).

Due its relative newness, one of the major difficulties that exists with respect to working within a Kaupapa Māori research approach is the lack of a collective understanding of what it is. Questions arise as to whether Kaupapa Māori research 
is a paradigm, methodology, epistemology, ideology, method, nga Kawa or something else. Therefore, I see it as of paramount importance to share the way in which I interpret Kaupapa Māori research.

In my own research experiences, although I did not see it at the time, I used Kaupapa Māori research as a kawa or set of guiding principles within the research process for my Masters Thesis. At the time, this met my dual need of wanting to conduct research with Māori rangatahi using culturally appropriate research practices and of conducting research within the norms of an academic institution. That is, using Kaupapa Māori research as a kawa ensured I was meeting not only the requirements of my research whanau in terms of conducting research that was relevant, culturally appropriate, and conducted in an environment that they felt comfortable in, but also allowed me to meet the requirements of the University.

Within this section on Kaupapa Māori research, it is important to clarify the meanings of a number of concepts in the context of this research paper. These concepts include Hui, whakawhanaungatanga and Bishop's (1996a) Initiation, Benefits, Representation, Legitimation, and Accountability (IBRLA) model.

Within my research process, I considered the Hui as an important medium in which to conduct research. Hui is the general term in Māori for any kind of meeting, but it most often refers to ceremonial gatherings on a Marae. Hui enable Mäori to work in culturally appropriate ways or ways determined by the group, when discussing the take or matter under consideration. The Hui is rich in cultural meaning, tikanga, and kawa, and fulfils the culturally important task of recognising the tapu and mana of all participants. During the Hui the flow of talk may seem circuitous, opinions may vary and waiver, but the seeking of a collaborative story and arriving at a jointly constructed meaning are central (Bishop, 1996b).

The concept of Whakawhanaungatanga, as suggested by Bishop (1996a), was also a major consideration in my interpretation of Kaupapa Māori research. Whakawhanaungatanga is the process of establishing relationships by means of identifying, through culturally appropriate means, your bodily linkage, your engagement, your connectedness and, therefore, your unspoken commitment to other people (Bishop, 1996a). In the research context whakawhanaungatanga is a metaphor that includes establishing whanau relationships, constructing a participant driven approach to power and control, and cultural consciousness. The establishment of a research whanau, although not necessarily by whakapapa, can help create a supportive environment where Māori participants feel more comfortable and can work in culturally appropriate ways. Further, by creating a metaphorical whanau relationship within Kaupapa Māori research, a researcher has similar responsibilities for and obligations regarding the knowledge and information that comes from the investigation, as if it had come from their own whanau. Participant driven approaches to power and control are addressed through the establishment of the research whanau and change the focus from the researcher as 'self' and the research participants as 'other' to one of collaborative research participants (Bishop, 1996a). Cultural consciousness takes into consideration cultural practices, tikanga, and protocols, and involves them in the research process.

Another important consideration when discussing Kaupapa Māori research is Bishop's (1996a) IBRLA model. This model addresses research issues for Māori in terms of initiation, benefits, representation, legitimation and accountability. Initiation is concerned with who initiates the research, why, and the goals of the 
research project. Benefits considers what benefits there will be, who gets those benefits, and what difference this research will make for Māori. Representation involves the consideration of whose interests, needs, and concerns the research examines and how this information is represented. Legitimation is concerned with the authority of the text and what happens to the results (Bishop, 1996a). Lastly, accountability considers who the researcher is accountable to, who has access to the findings, and who has control over how they are distributed.

\section{Focus Group Methodology}

Focus group methodology has become increasingly popular within research communities (Carey \& Smith, 1994; Morgan, 1995; Smith, 1995; Stewart \& Shamdasani, 1990). The focus group interview uses open-ended questions and allows individuals to respond without setting boundaries or providing clues for potential responses (Krueger, 1994). Krueger (1994) also describes focus groups as a "carefully planned discussion, designed to obtain perceptions on a defined area of interest in a non-threatening environment" (p. 5). Bouma (1996), on the other hand, defines focus groups as "combining the strengths of in-depth interviewing and observation in a group context" (p. 9). Taylor and Bogdan (1994) define indepth interviews as "repeated face-to-face encounters between the researcher and informants directed toward understanding informants' perspectives on their lives, experiences or situations as expressed in their own words" (cited in Minichiello, Aroni, Timewell \& Alexander, 1995, p. 68). In-depth interviews allow for a deeper sense of knowing and focus on the participants' interpretations of their experiences.

\section{METHODOLOGICAL PRINCIPLES}

The method used for this investigation was focus group methodology within a Kaupapa Māori research framework. It is important to note that there is no known published study that explicitly combines both Kaupapa Māori research and focus group methodology. Therefore, within this section, I describe a research process that adapted focus group methodology to 'fit' into a Kaupapa Māori research framework.

Befor $\epsilon$ moving on, it is important to clarify the roles of the Koroua and my supervisors within the research process. The role of the Koroua (or Koro) was to support the researcher and guide the research process in terms of cultural appropriateness. My supervisors' roles within the research process were to support the researcher and guide the research process in terms of University regulations and expectations for research. Because I was essentially working between the worlds of Māori and Pākehā, an initial research whanau including Koro, my two supervisors and me was established to guide the research process in terms of cultural appropriateness and University requirements.

I developed three key operating principles for the use of focus group methodology within a Kaupapa Māori research framework. The first principle centred on the focus group participants. The focus group participants were five Māori Rangatahi from Rotorua, aged 15-17 years. Koro and I decided that the best way to recruit participants for the study was to begin with our networks and ensure that we recruited participants from the same social network. That is, we did not look to attract individual recruits but, instead, approached several individuals and drew upon their potential to gain participants via their friendships and social 
networks. Recruiting participants in this way not only allowed the key participants to be part of the research process, but also allowed for the opportunity of ownership and a sense of comfort between participants. Ultimately, the five participants came from two separate but socially interconnected networks.

The focus group discussion within a Kaupapa Māori research approach included more than just the participants from the population of interest. The focus group participants within the research Hui also included my Koroua and supervisors, and anyone the actual participants brought with them in order to make themselves feel more comfortable in sharing their views. Although these support people did not necessarily participate in the discussion, their role was to provide support and ensure the research process was appropriate and guided in terms of cultural practices.

The second principle developed for the inclusion of focus group methodology within a Kaupapa Māori research framework related to my role as the researcher. My role within the focus group discussion was to not only facilitate the discussion, but also to share my stories. Contributing my stories to the discussion was intended to allow the participants to feel more comfortable sharing their stories and also to ensure that a collective story was told. With these first two principles in mind, the focus group within a Kaupapa Māori research framework functions as a metaphorical (research) whanau. All present at the research Hui came together to form a broader group that I have termed the research whanau for the purposes of this study. The research whanau was developed in terms understandable to all those involved and, therefore, we all had responsibilities within it.

The third principle was that the focus group discussion was held as part of a research Hui. Conducting the focus group discussion within a Hui format was developed to allow the participants to establish relationships and to ensure that significant cultural practices such as Karakia, mihi, the sharing of kai, and Poroporoake were practiced. By using the Hui as a means of negotiation and research whanau discussion, all participants had a chance to express their opinions and create the meaning of the take. The concept of the Hui describes the interactions between the participants within the interview or discussions and the process of arriving at an agreed collaborative story.

The focus group discussion was audio-recorded and the tapes transcribed. My supervisors also took notes to enable me to focus on building rapport and facilitating the group discussion. I also recorded my own first impressions within 24 hours of the Hui. I then analysed the information using a thematic approach which is described as searching through the information collected for regularities and patterns (Bogdan \& Biklen, 1992). Once I established some initial themes, I provided the research whanau with a copy of the preliminary analysis. At a second Hui, I presented the themes that emerged from the focus group discussion and sought clarification with participants to ensure that I understood and represented their views appropriately in terms of their intended meanings. Following the second Hui, the research whanau agreed on the refined themes and ideas and sanctioned me to represent our stories.

\section{THE RESEARCH PROCESS}

This section derives from my own observations, experiences, and perspectives of both the research process and discussions with my Koroua and University research supervisors. It provides a picture of the research process used to conduct 
an investigation of the leisure perspectives of Māori rangatahi in one research setting.

Conducting leisure research in a Hui format and using focus group methodology as the method for discussing the take created a collectivistic, culturally appropriate, Māori owned approach for studying Māori rangatahi perspectives. It also had the added benefit of the research being conducted by a Māori rangatahi, using a Māori preferred research approach, and working to benefit Māori rangatahi.

Within the context of Kaupapa Māori research, it is important to acknowledge that the research Hui was one part of a fluid and interconnected research process. That is, the research process started when I consulted a Koroua about the research I wished to conduct and ended when the research participants were provided with a copy of the final research document and were consulted on its further use.

As stated earlier, all of those present at the research Hui - including the five research participants, the Koroua, my two supervisors, a number of support people, and me as the researcher - all came together to form the research whanau for this investigation.

Koro started the Hui with a mihi and Karakia, firstly in Te Reo Māori and then translated into Te Reo Pākehā, as participants' understandings of Te Reo Māori were limited. With this important cultural practice completed, Koro moved on to discuss the purpose for the day and assured his guidance and support to the participants and me throughout the research Hui. In his role as the Kaumatua of the research whanau, Koro also provided permission and encouragement to the participants to 'talk' and share their opinions openly and honestly.

Once the official opening was conducted, all those present introduced themselves. Whakawhanaungatanga emerged through our introductions as the participants and I began to identify with each other through whakapapa and similarities in our backgrounds. From my own observations of the occurrences during this time, there seemed to be a degree of comfort or rapport amongst those present as shown by their relaxed postures and the presence of laughter. The research Hui had started out in a way we were all accustomed to due to our cultural experiences, and making connections in this way helped enable a feeling of 'comfortableness' to emerge.

The final part of the introduction period consisted of me introducing the research project, explaining the traditional informed consent form, the research programme, and how we would develop a research whanau agreement. Within the informed consent form, developed according to the University of Waikato guidelines, participants were assured of confidentiality and asked if they had any problems with those people not directly involved in the study being present during the discussion. With no disagreements or questions from the focus group participants the informed consent was collectively signed by all present.

The research whanau agreement went beyond the usual boundaries of a focus group because it provided the participants with the opportunity to contribute ideas in their own words on what they wanted to happen within the focus group discussion. Examples from the collectively agreed principals of behaviour included 'respecting what each other has to say, don't worry about what others think and don't put anyone down'. This agreement was again collectively signed by all present.

The focus group discussion centred around finding out the perceptions, experiences, and interpretations the Mãori rangatahi had with respect to leisure. 
Although Koro, my supervisors and I had collaboratively developed a guide of open-ended questions to start the discussion, the format of the Hui was intended to allow participants to choose the way they wished to respond to questions and to direct the discussion.

The focus group discussion, from my point of view, had a somewhat nervous start, as I was not confident with my own facilitation skills. The feelings I was having also appeared to impact on the research whanau, as the questions I asked were tentatively answered by the rangatahi. With a number of questions concluded we stopped for kai.

While we shared kai two informal discussions took place that are of relevance to the success of the research process. The first discussion was between the participants and I. We talked about a range of things including mutual sharing of similar leisure experiences, a process that allowed for the further development of connection and whakawhanaungatanga with one another.

The second discussion involved my supervisors and I. They suggested that what I called a 'nervous start' was not so much a problem of getting the participants to talk, but rather of my reluctance to delve deeper. Three specific points from this conversation were of assistance, including the need for me to disclose myself in the way I would like the participants to, that I needed to delve deeper into the comments the participants made, and that I should facilitate the discussion as if they (my supervisors) were not present.

After the sharing of kai, we moved back into the formal focus group discussion. Due to the depth of stories I wanted to gain from this next session, I started by sharing a specific leisure experience which I hoped, based on our earlier informal conversation, that the participants could relate to in order to make them feel more comfortable in sharing their stories. Once I shared my first story, they all appeared to feel more comfortable and began to tell their stories. Where appropriate I later shared my own experiences when they connected with theirs to further encourage an open discussion. At the conclusion of the focus group discussion, all present participated in a Poroporoake and Koro ended the Hui by thanking all present for their contribution and closed the day with a Karakia.

\section{REFLECTIONS ON THE RESEARCH PROCESS}

Before moving into my reflection on the research process, it is important to note that it is not the purpose of this article to declare that focus group methodology is the research approach that should be used to conduct leisure or other educationrelated research with Māori rangatahi. Rather, it is my aim to share my experience of conducting leisure research with a small group of Rotorua Māori rangatahi, in the hope that this may encourage or help others to conduct future research with similar groups in a culturally appropriate way.

There are a number of characteristics of the research process that I identified as being of importance in the success of this research approach in a Māori setting. These characteristics include carrying out the focus group discussion within a Hui context, the establishment of a research whanau with participants, and my characteristics as the researcher.

The Hui setting in which the study was conducted was important in that it allowed the research to be conducted in a culturally appropriate way. That is, the incorporation of Māori cultural practices such as mihi and Karakia allowed the research whanau to work in terms that were understandable, comfortable, and culturally relevant. 
The sharing of kai as a fundamental Māori cultural practice was also included within the research Hui. The sharing of kai allowed for a much needed break in the focus group discussion as well as an environment that promoted informal conversations. The conversations that arose over the sharing of kai formed an integral part in the research process, and it allowed a space for the development of further rapport and whakawhanaungatanga between those present.

The establishment of the research whanau was also an important characteristic in terms of incorporating focus group methodology into a Kaupapa Māori research framework. The research Hui in many respects provided a space for the development of the research whanau. Factors that assisted with establishing the research whanau included the way in which Koro and I recruited participants and the resulting familiarity between participants.

Although Krueger (1994) suggests that for focus groups to be successful participants need to be unfamiliar with each other, we deliberately selected participants who were familiar with each other. For example, the selection of the Māori rangatahi for this study rested with two key participants who recruited the other three participants from their own social networks. I believe that the familiarity between participants did not deter from the focus group discuissions' success. Rather, the familiarity between participants actually seemed to work as an advantage in the focus group discussion as there was already an established rapport between participants. It became, therefore, my responsibility, as the facilitator of the discussion, to gain access into the relationships that already existed.

Although the purpose of the focus group discussion was of interest to myself, I also needed to recognise that the discussion had to be of interest to participants. While a number of pre-determined questions were developed as a guide, the participants had control over the information they shared and, as the focus group progressed, their responses determined the questions that were asked and the stories that were shared. This aspect of participants controlling the discussion links with Bishop's (1996b) concept of "a participant-driven approach to power and control" (p. 222). The way in which this research was conducted allowed the research whanau to have shared control over the focus group discussion.

In relation to this, the focus group discussion also took on a collective approach in that power and control was shared within the research whanau. Although Koro was in many respects the cultural leader he also shared his power with not only me as the researcher, but also the entire research whanau. This was obvious in the way Koro encouraged the research whanau to share their opinions openly and honestly and by his giving me the floor to facilitate the discussion. My role as the facilitator was like any other in the research whanau. That is, I also had to share my stories with the research whanau if it was my expectation that they disclose themselves within the discussion in a reciprocal way.

The last consideration that enabled the incorporation of focus group methodology into a Kaupapa Māori research is my characteristics as the facilitator. It is important to acknowledge that I may have had privileged access to the information provided in the focus group discussion, which could have led to the willingness of the participants to divulge their thoughts within the research methodology. Jourard (1964) suggests that participants are more likely to disclose to individuals who resemble them. I believe my characteristics as the facilitator encouraged participants to share their stories and perspectives in the focus group discussion. That is, my being a Rotorua Māori rangatahi and sharing a similar background and life experiences with the participants may have enabled 
participants to feel more comfortable in sharing their views. Further, establishing a connection with participants based on shared experiences, phrasing questions and later results in language they understood, and being able to respond in a language chosen by them may have enhanced the success of the focus group discussion.

\section{A STEP INTO THE LIGHT}

$\mathrm{Ka}$ pu te ruha ka hao te rangatahi

This article has provided a step into the light in terms of suggesting a culturally appropriate research approach to conduct leisure research with Māori rangatahi. The findings of this article, based on conducting leisure research with a small group of Rotorua Māori rangatahi in one setting, indicates that focus group methodology can be incorporated into a Kaupapa Māori research framework. Further the research approach of incorporating focus group methodology into a Kaupapa Māori research could be a valuable consideration for future research with Māori rangatahi.

\section{ACKNOWLEDGMENTS}

The author would like to take this opportunity to thank the participants, Koro, my whanau, and my supervisors of my Thesis, Lisa Hayes and Clive Pope, and my directed study, Toni Bruce and George Salter, for making this paper possible. No reira koutou ma, he mihi aroha tenei ki a koutou, nga kaitautoko o te Kaupapa nei, tena ra tatou katoa.

\section{GLOSSARY}

It is important to note some Māori words have multiple meanings. Therefore, the English translation that is provided in this glossary is based on the context in which it was used in the text of this article, and the nearest English translation.

Aotearoa

Hapu

Hui

Iwi

Kai

Karakia

Kaumatua

Kaupapa Māori

Kawa

Koroua/Koro

Mana

Māori

Marae

Mihi

Pākehā

Poroporoake name that Kupe (a Māori explorer) gave this land we now call New Zealand

sub-tribe

to gather or meet

tribe, people

food

prayer/chant recited to clear the way for a new activity respected Māori elder

Māori agenda

protocol or set of guiding principles

a name given to a Māori elder as a mark of respect

integrity, charisma

indigenous people of Aotearoa

meeting area of whanau or iwi, where formal greetings and discussions take place

greet, introduction

non-Māori, New Zealander of European descent

farewell, closing 
Kaupapa Māori research

Rangatahi

Take

Tapu

Te Reo Māori

Te Reo Pākehā

Te Tiriti O Waitangi

Tikanga

Waka

Whakapapa

Whakawhanaungatanga

Whanau
Māori approach to research

young people

topic, subject or matter being discussed

sacred

the language of the Māori

the English language

the Māori translation of the Treaty of Waitangi signed in 1840

customs, values and beliefs

canoe

genealogy

process of establishing relationships through connectedness

family

Ngongotaha te Maunga, Rotorua nui a Kahumatamamoe te Moana, Te Arawa te Waka, Te Arawa te Iwi, Ko Ngati Whakaue me Tuhoe oku hapu, Te Papa I Oru te Marae, No Rotorua ahau, Ko Geraldine Hera taku ingoa, No reira, Tena koutou, Tena Koutou, Kia ora mai tatou katoa.

Ngongotaha is the Mountain, Rotorua nui a Kahumatamamoe is the water, Te Arawa is the Waka, Te Arawa are the people or tribe, Ngati Whakaue and Tuhoe are the sub tribes, Te Papa I Oru is the Marae, I am from Rotorua, my name is Geraldine Harvey, greetings to all these things.

Ka pu te ruha ka hao te rangatahi

The old net lies in a heap, while the new net goes fishing

\section{REFERENCES}

Bishop, R. (1996a). Addressing issues of self-determination and legitimation in Kaupapa Māori research. He paepae korero: Research perspectives in Māori education. Wellington, New Zealand: New Zealand Council for Education Research.

Bishop, R. (1956b). Whakawhanaungatanga: Collaborative research stories. Palmerston North, New Zealand: Dunmore Press.

Bogdan, R. C., \& Biklen, S. K. (1992). Qualitative research for education: An introduction to theory and methods. Boston: Allyn and Bacon.

Bouma, G. D. (1996). The research process. London: Oxford University Press.

Carey, M. A., \& Smith, M. W. (1994). Keeping the group in focus group research. Qualitative Health Research, 4, 123-127.

Jahnke, H., \& Taiapa, J. (1999). Māori research. In C. Davidson and M. Tolich (Eds.), Social science research in New Zealand: Many pathways to understanding. Auckland, New Zealand: Longman Paul.

Jourard, S. M. (1964). The transparent self. Princeton, NJ: Van Nostrand.

Krueger, R. A. (1994). Focus groups: A practical guide for applied research (2nd ed.). Thousand Oaks, CA: Sage.

McConnell, R. (2000). Māori, the Treaty of Waitangi and sport: A critical analysis. In C. Collins (Ed.), Sport in New Zealand society. Palmerston North, New Zealand: Dunmore Press. 
McGregor, H., \& McMath, M. (1993). Leisure: A Māori and Mangaian perspective. In H. C. Perkins and G. Cushman (Eds.), Leisure, recreation and tourism (pp. 4457). Auckland, New Zealand: Longman Paul.

Minichiello, V., Aroni, R., Timewell, E., \& Alexander, L. (1995). In-depth interviewing (2nd ed.). Thousand Oaks, CA: Sage.

Morgan, D. L. (1995). Why things (sometimes) go wrong in focus groups. Qualitative Health Research, 5(4), 516-523.

Smith, A. (1998). Māori and leisure: A survey. In H. C. Perkins and G. Cushman (Eds.), Time out? Leisure, recreation and tourism (pp. 51-63). Auckland, New Zealand: Longman Paul.

Smith, C. W. (1994). Kimihia te maramatanga: Colonisation and Iwi development. Auckland, New Zealand: Te Whare Wananga O Tamaki Makaurau.

Smith, G. H. (1992). 'Tane-Nui-a-Rangi's legacy ..... Propping up the sky': Kaupapa Māori as resistance and intervention. Conference proceedings: New Zealand Association for research in education/Australia Association for research in education joint conference. Deakin University: Melbourne, Australia.

Smith, L. T. (1999). Decolonising methodologies: Research and indigenous peoples. Dunedin, New Zealand: University of Otago Press.

Smith, M. N. (1995). Ethics in focus groups: A few concerns. Qualitative Health Research, 5(4), 478-486.

Stewart, D. W., \& Shamdasani, P. W. (1990). Focus groups: Theory and practice. Thousand Oaks, CA: Sage.

Thompson, S., Rewi, P., \& Wrathall, D. (2000). Māori experiences in sport and physical activity: Research and initiatives. In C. Collins (Ed.), Sport in New Zealand society (pp. 241-255). Palmerston North, New Zealand: Dunmore Press.

Walker, R. (1990). Ka whawhai tonu matou: Struggle without end. Auckland, New Zealand: Penguin Books. 